\title{
Music, language and literature
}

\section{Language and music}

The divergent interpretations of the relationship between music and language in modernity are inseparable from the main divergences between philosophical conceptions of language. The attempt to explain language in representational terms in the empiricist tradition that eventually leads to analytical philosophy, and the understanding of language as a form of social action and as constitutive of the world we inhabit in the hermeneutic tradition give rise to very different conceptions of music. One paradigmatic contrast has emerged in the preceding chapters, which can somewhat crudely be summarised as follows. On the one hand, music can be regarded as a deficient means of articulation in relation to the kind of possibilities for manipulating and changing the world for human purposes offered by verbal language. On the other, it can itself be regarded as a kind of language - which can even be privileged above verbal language - because it reveals aspects of being in the world that verbal language is unable to reveal. Schleiermacher's work offered a pragmatic way of understanding different forms of articulation which did not require a wholesale split between verbal language and music; it also elucidated important differences between the way each can come to be employed and can affect its recipient. From this perspective the - hyperbolic - alternative of regarding music as 'higher' than verbal language for metaphysical reasons makes sense in relation to a specific historical situation, namely one in which the universalising nature of verbal language is felt to be inadequate to the individual experience of the modern subject. In this view the practice of musical production and reception offers a universally accessible means of articulation which at the same time involves the subject in an individual manner. Musical 'vocabularies' can therefore serve vital purposes in disclosing affective and other significance that other forms of articulation and communication may not be able to disclose.

The very fact that this is a specifically modern conception suggests how vital it is for philosophical views of this issue to get away from the idea that there could be a definitive theory of how the semantic relates to the musical in language, or of the difference between verbal language and music. Such a theory would require a representationalist account of what each 'really is', and 
this would simply repeat the problems associated with such positions in explaining why such supposed 'entities' as music keep changing so radically. What is needed instead is a conception which takes account of the interaction between what gets talked about as music and what gets talked about as language, these being quantities which are never wholly separable anyway. This interaction has generally been seen, for example by Hegelians like Carl Dahlhaus, in terms of the effects of conceptual shifts upon the nature of musical composition. What is significant in the period we have focused on so far is that music itself helps to change conceptions of language. It obviously does so for a conceptual reason: language ceases to be regarded in purely representational terms during this period. However - and this is the vital point the roots of this conceptual shift themselves also have to do with the effect of new kinds of autonomous music. Dahlhaus himself reveals the importance of the rise of the idea of 'absolute music'. He tends, though, to underplay the ways in which this idea also results from what is achieved by new musical practices. These practices are not solely the result of conceptual reflection and arise rather from the more intuitive, expressive and pragmatic aspects of musical composition and performance.

Hamann's and others' idea that the first language was music was itself a manifestation of a dissatisfaction with the idea of language as representation of a ready-made world. Once one becomes aware of the world-disclosive nature of language it becomes possible to understand language in the wider sense of comprehensible articulation that I proposed in the preceding chapters. This makes it possible to understand music as language without falling into the trap - sometimes encountered in 'new musicology' - of trying to reduce music's content to a verbal equivalent. ${ }^{1}$ How, though, are we to establish a useful contemporary, but historically informed, way of approaching the interaction between the verbal and the musical which does not lead to the kind of rigid divisions that, until recently, have made the analytical tradition so incapable of saying anything much about music that really matters?

The links I have tried to establish between Romantic thought and contemporary pragmatism can be of further help here. A vital part of Rorty's conception of language is suggested by his question: 'At what point in biological evolution did organisms stop just coping with reality and start representing it?' His answer is: 'Maybe they never did start representing it' (Rorty 1999 p. 269). In consequence: 'there was no decisive moment at which language stopped being a series of reactions to the stimuli provided by the behaviour of other humans and started to be an instrument for expressing beliefs' (p. 74). At this level there can be no fundamental difference between, say, rhythmically based verbal or proto-verbal communication, and something which can eventually become aesthetically significant music (though we can question Rorty's - and others' - impoverished notion of subjectivity as mere reaction for doing too little to account for the genesis of significant new reactions). The sort of line Rorty (who never discusses music) would probably draw between verbal lan- 
guage and music relies on the idea of the development of 'semantical metalanguage', in which language use is distinguished from mere instinctual expression by the fact that we can 'say things like, "It is also called ' $\mathrm{Y}$ ', but for your purposes you should describe it as X"' (Rorty 1999 p. 65). One of the key functions of verbal language is, then, to enable language-users to pick out different aspects of objects for human purposes, which entails the ability to use metalanguage.

Music, in contrast, can really only pick out aspects of the world of objects in a very limited manner, such as when it functions as a signal for getting up because it is morning. Music may, however, be able to function in something like a metalinguistic manner at affective and other levels. The simplest kind of instance of this is ironic music, that metalinguistically says: 'I am not saying what I seem to be saying.' An example of this would be Mahler's march music, which takes up a kind of music often positively associated with the military and undermines its military connotations. Like verbal irony, musical irony clearly relies on a whole series of contextual assumptions which are not fixed and which change historically, but once one accepts that meaning is never atomistic, but always contextual, music can function in an analogous manner to words in this respect. Beethoven's String Quartet op. 135 functions in a metalinguistic manner in its last movement by using closely related musical material both to ask an apparently serious question about life and death, and to answer it in an essentially humorous manner. Beethoven wrote the words 'Must it be?' and 'It must be' above the music at these points, but they need not determine a listener's way of hearing how the very differing kinds of music comment on each other. The listener may, furthermore, not be able to state verbally what they think this relation between the question and answer means. Indeed, they may not even be explicitly aware of the relationship between the musical material of the introductory question and the answer, but they can still gain a sense of meaning from the piece's change of mood. The relation of mood to meaning is also vital in poetry, where the interaction of metaphors can create an affective climate which cannot be inferred from what the poem says propositionally, and which relies on the phonic and rhythmic organisation of the words as much as on their meaning. A perhaps rather over-used example of this would be Goethe's 'Über allen Gipfeln ist Ruh', where the semantic content is minimal but the sound patterns and cadences of the verse both amplify the semantic content and take it into the realm of something like music.

The underlying issue here is the way in which patterns of identity and difference, which are not semantically determinate, but which are world-disclosive, are shared by musical and linguistic forms. These patterns will function differently in different practices, but they rely on an interaction of two dimensions of articulation. The increased attention to the musical qualities of words occasioned by the great Romantic composers in some nineteenth-century poets, like Mallarmé, is one example of such cross-fertilisation, as are aspects of Beethoven's declamatory and rhetorical styles in relation to the dramas that impressed him. How, then, do these issues relate to Foucault's contention we 
saw in Chapter 6, that a major change took place in language at the beginning of the nineteenth century?

Foucault regarded this change as marking the threshold between 'Classicism', in which words and representations intersect, and modernity, where language is no longer tied to representation. His argument is oriented towards the developments in literature which lead to 'poésie pure' and to the possibility that 'language may sometimes arise for its own sake in an act of writing that designates nothing other than itself' (Foucault 1970 p. 304). Foucault's version of the story of theoretical reflection about language omits any mention of Hamann, Schleiermacher or Humboldt: his examples are Grimm, Bopp and, somewhat oddly, as we shall see later, Friedrich Schlegel. His claim is that: 'Literature is the contestation of philology (of which it is nevertheless the twin figure: it leads language back from grammar to the naked power of speech)' (p. 300). The argument is dialectical: 'Literature' comes into existence because of the emergence of the other of itself, the science of language. In the same passage Foucault relates Mallarmé's poetry to this process, characteristically giving language the attributes of subjectivity: 'To the Nietzschean question "Who is speaking?" Mallarmé replies - and constantly reverts to that reply - by saying that what is speaking is, in its solitude, in its fragile vibration, in its nothingness, the word itself - not the meaning of the word but its enigmatic and precarious being' (p. 305). Foucault's account could also apply to the relationship between language and music: a word minus the kind of meaning that semantics tries to provide in terms of truth conditions can play a similar role to a note in a piece of music. Lévi-Strauss talks of musicality as 'Language minus meaning', and Novalis and Schopenhauer think of music as a 'universal language'. Music overcomes the lack of a philosophical master vocabulary by communicating, in a manner that transcends what can be said in the vocabulary of specific natural languages, ways of being which are universal; at the same time, music is a highly specific form of articulation. However, the question with regard to Foucault's claims is what the 'being' of the word/note says if it does not relate to the subject that is threatened by loneliness and fragility. Foucault seems just to be committing a strange version of the pathetic fallacy, with the word taking the place of some aspect of nature onto which human feelings are projected.

In The Order of Things Foucault's structuralist exclusion of the subject relies upon a Heideggerian account of subjectivity as the locus of domination of the other, of the kind that has already been seen to be inadequate to the thought of this period. If one looks at the development of the idea of literature in German philosophy in the early Romantic period in relation to music perspectives on these issues become available which offer an account of subjectivity of the kind lacking in so much recent theory (see also Bowie 1997). Foucault concentrates on that aspect of thinking about language which fits his thesis about the emerging new 'episteme', the fact that language itself becomes an object for science and therefore generates a counterpart, 'Literature', which cannot be such an 
object. It is, however, evident from what we have seen in Hamann and his successors that a different view of language also emerges in the theory of the time, most notably in Schleiermacher. According to this view it is impossible for language to be wholly transparent to a science of language, because there can be no 'general language' that would be able to be the master code for the other languages. Part of the reason for this is that the 'musical' is an ineliminable aspect of language: it can be foregrounded so that the semantic aspect of language almost wholly recedes, coming close to what Foucault suggests in answer to the question of who is speaking. The problem is how one interprets this move away from the semantic to language without 'meaning'.

Despite the central role of music in this area it is a topic that Foucault, like Heidegger (and unlike Mallarmé), hardly ever seriously discusses in print, even though he was very interested in it. He is not alone in this reticence. The difficulty of engaging with music on more than an analytical level, which has fuelled much recent debate in musicology, is an index of precisely what is at issue here in the relationship between music and language. The fact that even musical performers are often signally inept at enlightening others in words about music which they can perform in a revelatory manner further underlines the tensions in the understanding of this relationship. These tensions are germane to the issue of subjectivity and language. As I have tried to show, the peculiar nature of music can help reveal the weaknesses of conceptions of subjectivity which are limited to the idea that what can be communicated is ultimately propositional - good conductors can, for example, by the use of all kinds of gestures and expressions, get music to go the way they want without using any words at all. ${ }^{2}$ Music's relationship to non-verbal forms of communication and expression has led to it being neglected both in some recent theories of language, and in the history of aesthetics, where left-wing theorists, with some exceptions, such as Ernst Bloch and Adorno, have often either attempted to reduce it to its ideological context or have regarded it as, in Thomas Mann's phrase, 'politically suspect'. Music's non-representational character too often leads to it being disqualified as something which has not attained the seriousness of real thinking and praxis.

An admittedly questionable passage from Freud - do 'primitive languages' really have no grammar? - can suggest why the language of music may be regarded as suspect in this way: 'All the linguistic means via which the finer relations of thought are expressed, the conjunctions and prepositions, the changes of declination and conjugation, lapse, because the means of representing them are lacking; as in a primitive language without a grammar, only the raw material of thought is expressed' (Freud 19821 p. 462). Freud is actually referring not to music, but to dreams. The applicability of his description to wordless music connects the 'royal road to the unconscious' to what makes articulating the relationship between language and music such a problem. ${ }^{3}$ In much the same way as Wittgenstein claimed that the structures of the understanding of music and of language were not wholly separate, Freud's comment can be used to suggest 
how the working of self-consciousness also relates to what music and dreams can do that the more 'grammatical' aspects of thought cannot.

One of the decisive issues in the present book has been how consideration of the theme of aesthetics and subjectivity offers ways of understanding the role of the natural sciences in modern culture. It seems no coincidence that music itself embodies precisely the kind of relationship between what is accessible to scientific explanation and what is not that is decisive for understanding that role. On the one hand, the basis of Western music, the diatonic scale, relies on mathematically expressible proportions, which derive, in certain respects at least, from what is also the foundation of the modern scientific world view. On the other hand, music, especially in the modern period, takes on a vital role in relation to the emotions. It moves from being regarded in the first half of the eighteenth century as merely a manner of representing already familiar feelings, to being seen in the second half of that century, and in much of the nineteenth century and since, as being able to give rise to and articulate new kinds of feeling (see Bowie 2001a). The openness of music to the new technologies makes it clear that production and reception of music engage the understanding, Kant's faculty for rules. At another level, music also engages the individual subject in ways which relate to the notion of 'feeling' as developed by Novalis, Schlegel, Schleiermacher and others. Feeling can never be represented as such, but is a motor for finding means of articulation which are not prey to the inadequacy of verbal language to certain fundamental aspects of our being.

Music can be understood, therefore, as functioning in terms of a kind of dialectical 'identity of opposites'. The mathematical and the affective are both essential to it, but the former is universal, the latter individual. The temptation to use music as the means of access to an absolute which would overcome the division between the mathematically explicable, deterministic nature manifest in the rules of the harmonic series, and the world of affect is apparent in this combination of extremes. ${ }^{4}$ Such a means of supposedly revealing the absolute does not, of course, result in a representation or a philosophical articulation of how necessity and freedom can be reconciled. This theoretical lack can be understood both as a source of the power of music and as a reason why music can come to be regarded as socially and politically dangerous. Instead of offering a rationally comprehensible account of our place within things, music is regarded as suspending or transcending discriminations that are inherent in the identifying nature of conceptual thought. Such extreme claims about music in modernity also suggest a strange possible consequence for philosophy. If truth is supposed to be inherent in the word, anything which suggests that the word is no longer fully adequate as the expression of the highest truth opens up a very different path for philosophy. This idea may be hyperbolic, but it does suggest a kind of power which music seems able to exercise that verbal language may not. How this power is exercised and understood is, though, what makes music a political as well as a philosophical issue. The history of music's role as a social and political practice in the modern period is often related to the fact that its 
distance from determinate representation can make it an adjunct of forms of social deception, from the use of music in Nazi rallies, to use in modern advertising. At the same time, however, music can also be a means of resisting the thinking behind such deceptions, via its ability - which depends precisely on its non-representational nature - to refuse to follow established patterns of sensemaking and articulation in a society. These complex issues can be explored if we look further at some of the ways in which music has been understood in German philosophy.

\section{Hegel and Romanticism: music, logos and feeling}

In contrast to the late eighteenth- and nineteenth-century thinkers who give music a central role - such as the early Romantics, Schopenhauer and Nietzsche - Hegel, as we have seen, regards music, like the rest of the arts, as a subordinate manifestation of truth. In order to put Hegel's response to music in an appropriate context we need now to take a further look at changes in the understanding of music in Hegel's time. Carl Dahlhaus explores these changes in Die Idee der absoluten Musik (The Idea of Absolute Music). At the end of the eighteenth century the idea of the superiority of music with a vocal text increasingly loses currency and 'conceptless instrumental music - and precisely because of and not despite its lack of concepts - was elevated to a language above verbal language' (Dahlhaus and Zimmermann 1978 p. 179). The preceding conceptions of music had Platonist roots. Music consisted of Harmonia, Rhythmos and Logos: 'By Harmonia one understood regulated, rational relations of notes brought into a system, by Rhythmos, the temporal order of music . . . and by Logos, language as the expression of human reason' (Dahlhaus 1978 p. 14). Importantly, composers, such as Haydn, had already begun to undermine this conception in praxis, before the move away from the conception began to be articulated theoretically. ${ }^{5}$

The idea of Logos, whether in the form of a liturgical text or of the words of a song, is still basic to Hegel's conception. Although he evidently enjoyed music, Hegel did not regard it as being particularly important. His remarks in the Aesthetics are in some respects most notable for how they epitomise a view of music which plays a role in much subsequent aesthetic theory, particularly in the Marxist tradition. Hegel's description of music is also echoed in Foucault's Mallarmé-derived notion of the 'act of writing that designates nothing other than itself'. Hegel, though, draws the opposite conclusion to Foucault about the value of such an act. In the section of the Aesthetics on 'Independent Music', music without words, Hegel claims: 'Subjective inwardness constitutes the principle of music. But the most inward part of the concrete self is subjectivity as such, not determined by any firm content and for this reason not compelled to move in this or that direction, rather resting in unbounded freedom solely upon itself' (Hegel 1965 II p. 320). The structure of the argument should be familiar from what was said about the Logic in Chapter 5: 'subjectivity as such' 
is analogous to being at the beginning of the Logic, which must come to itself by self-division. Only when being has been articulated in the concept can it become being for itself as the absolute. Subjectivity is likewise only able to realise itself via engagement with objectivity, as the structure of reflection in the other makes clear. The principle of music may be 'subjective inwardness', but this requires its objective other to be externalised as sound and thus to be music at all. Music's insufficiency lies for Hegel in the fact that the externalisation in question takes place in the transient medium of sound.

For Hegel, purely 'musical music' has to free itself from the 'determinacy of the word'. However, instrumental, wordless, music will only really appeal to the expert, who will enjoy it because he can compare the music he hears with 'rules and laws he is familiar with' (II p. 322). There is, then, little sense here that music may in some circumstances be able to 'say' what other means of articulation are unable to. The expert will try to find 'more distinct ideas and a more familiar content' in the music, and 'In this respect music becomes symbolic for him, but in attempting to grasp the meaning he is faced with puzzling tasks which rush quickly past, which are not always amenable to being deciphered and are capable in fact of the most various interpretations' (II p. 322). Statements like this make it clear how Adorno's objections to Hegel's neglect of the 'non-identical' in art derive not least from Hegel's failure to see more in the problem of understanding music than a deficit on the part of music itself. Furthermore, being 'capable of the most various interpretations' is probably the most apt description of significant literature in modernity - indeed, as Schleiermacher indicated, it is also a possibility for any kind of text. Given its interpretative history, Hegel's own work can hardly be said to be very different, in this respect at least, from music. Part of what he means is, of course, simply based on the transience of the playing and hearing of music, as opposed, say, to the physical persistence of a text or a painting. However, pieces of music are actually idealisable in much the same way as texts are. I can keep the patterns of the movement of a symphony in mind, or if I have the right sort of training, of a piece of improvisation, in much the same way as I can that of a novel, and in listening to one or reading the other in real time I am subject to temporality in much the same way. ${ }^{6}$ As such, it would seem that much of Hegel's objection comes down to the fact that music is not representational and referential in the manner of verbal language. Hegel's objection epitomises the way conceptions of language begin to diverge in this period.

This divergence is evident in the fact that Hegel's conception of the musical note is echoed in Mallarmé's idea of the pord's 'fragile vibration': it is 'an expression which precisely by the fact that it is externality immediately makes itself disappear again' (II p. 262). ${ }^{7}$ The body which vibrates to produce the note is negated in its static state, but returns to this state once the note has passed. The body persists where the note does not, although it is displaced when it vibrates - the body functions here rather like being in the Logic, which only becomes something when it is negated. Consequently the body's truth lies, not in its inert 
facticity, but in the movement that takes it beyond itself, propelling it into a relationship with itself as at one moment present in one place, and at another in another place. In order to sustain a radical difference between music and Logos, Hegel has to argue that the ideal content of a word can survive this 'fragile vibration' in the same way as the Idea overcomes the transience of its objective embodiments. This is precisely what Foucault denies is the case for what he sees as philosophically the most significant development of language in modernity. For Hegel the note 'admittedly also does have a content, yet not one in the sense of the visual arts or literature; for what it lacks is precisely objective formation [Sichausgestalten], whether it be formation into forms of real external appearances or into the objectivity of spiritual intuitions and ideas' (II p. 261). The note lacks both persistent objective existence and persistent ideal existence. A painting or the ideas about the external social world in a novel do not suffer from this kind of lack, though they are tied to the particular in a way music is not. The implication has to be that the philosophical word can overcome even the deficit inherent in artistic forms which engage with the particulars of the world. Philosophy can achieve the 'presence' those particulars lack because of their dependence on other particulars.

Music, then, fails to reach the level which is the result of the real interaction of subject and object whose structures philosophy articulates, and so remains just 'subjective'. We shall see later that Hegel makes the same point against what he understands to be Schlegel's conception of irony, because it also fails to test itself against the real resistance of the objective world. In irony everything is 'produced by the subjectivity of the ego' (I p. 72) and can therefore just as easily be destroyed by it. Whereas the plastic arts 'take up the forms of a broad, multiple world of objects into themselves', the note is 'completely abstract' (II p. 261). However, Hegel's own claims are strangely analogous to the objections Schelling made against the intransitivity of the end of the Logic, where, as Schelling put it, the Idea 'has no need any more to become real any more and in any other way than it already is' (Schelling I/10 p. 152). Hegel thinks that the Idea is able to reveal itself as what can overcome the contingency of being by 'releasing itself into nature'; it seems once again, though, that its actual status may in some respects be closer to music. What is most convincing about Hegel's conception is the way in which it conveys the inherent dynamic of thinking, in a manner akin to a Beethoven symphony. Evidently such a claim only deals with one dimension of what Hegel achieves, but, as we saw, if his claim that the Logic exhaustively reveals the ways in which being can be articulated turns out to be unjustifiable, the ultimately representational aim of his philosophy remains unfulfilled, even though the internal dynamics of his thought still have much to offer. The questions about Hegel's ultimate aim necessarily affect the viability of his conception of language, and thence his conception of music. The way Hegel relates text and music can suggest how.

For Hegel the text which accompanies music or which music accompanies 'gives certain ideas and thereby tears consciousness away from that more 
dreamy element of feeling without ideas' (Hegel 1965 II p. 306). - He does insist, though, that the music must also retain its own autonomy and not just be there in the service of a content dictated by the text. He considers philosophical comprehension of the conceptual work of the understanding to be the route to the absolute. Music can never attain this higher status because it is an expression of 'feeling' (Empfindung). 'Feeling' is 'immediate' because it does not separate the subject that intuits from the object of intuition, as we do in conceptual thinking by ascribing differing predicates to an external object in terms of its inferential relations to other objects. Like a dream, feeling is wholly within the subject. However, something is missing here. Music can clearly change my way of relating to the world of objects by offering new affective, rhythmic and other resources, of a kind that are also available in poetic usage, but not necessarily in more instrumental uses of language. Hegel's view therefore fails to be adequate to the phenomenon in question. If language is not conceived of representationally the borderline Hegel sets up here ceases to be plausible because music and language can each achieve similar, or perhaps at times even identical effects. The interaction between music and the subject is not ultimately reducible to what can be verifiably said about it, thus to an account from the objective, conceptualisable side of the relationship, of the kind sought in some kinds of music psychology. At the same time, it is not the case that the effects of this interaction merely remain in 'that more dreamy element of feeling without ideas'. This would only be the case if feelings were wholly indeterminate. In that case, there could only be one feeling, rather than the endless gradations of which feeling actually consists. The role of music as a social practice that is evident, for example, in music therapy, which brings people back into contact with the social world, or in the way we can apprehend 'musical ideas' and deepen our comprehension of them both in words and in the practice of listening or playing, makes it clear that drawing strict lines here obscures some important aspects of the relationship between verbal language and music. One could say, then, that Hegel's account is 'insufficiently dialectical'. For Hegel feeling, as something immediate, can only reach its truth when it is comprehended in the concept. The question is whether feeling is reducible to what can be said about it. On some occasions feeling may only become itself by being expressed in words, on others feeling may only be accessible to a non-verbal form of articulation.

The difficult problem here is exactly how the immediate aspect of feeling relates to forms of music production and reception which are themselves conceptually mediated but can never be definitively described in verbal terms. The neo-Hegelian version of the rejection of immediacy was, as we have seen, directed against the idea that something directly given from the world could determine the truth or falsity of what we say. I argued in Chapter 6 that the argument against immediacy would seem to apply to the inferential nature of knowledge of the world, but not to the immediate awareness that the Romantics termed 'feeling'. In an essay on Sellars, Robert Brandom makes a distinction between differential responses to a stimulus, of the kind a photocell can make 
into relation to red and non-red things, and the conscious perception of something as red, which relies on knowing the 'inferential significance of applying the concept red ... that it is coloured, not a prime number, and so on' (www.ditext.com/brandom). A note can be registered in terms of differential response to its frequency, but, as Hegel argues, it only becomes a note via its relation to a series of contexts, in which it is defined by its function. However, even this function is accessible in one respect to a complex differential response of the kind a computer can perform in relation to a score. What makes the note into part of a piece of music is, though, not adequately grasped either by the idea that we know the inferential significance of saying that it is such because it relates to other notes in a rule-governed manner, or even by the idea that we know it is music because we grasp the conceptual content of the term music can that content really be arrived at by music's being sound, not being painting, etc.?

It is at this level that the immediacy of feeling still seems to play a decisive role, of the kind Cascardi rightly regards as essential to the aesthetic. Stanley Cavell suggests another way of considering immediacy in this connection, when he claims that 'It is essential in making an aesthetic judgement that at some point we be prepared to say in its support: don't you see, don't you hear, don't you dig? .. . Because if you do not see something, mithout explanation, then there is nothing further to discuss' (Cavell 1976 p. 93). The content of what is at issue here is neither exhausted by the justifiable application of the term music, nor by all we can come to know about the sounds in question. This kind of excess of the affective and other content of music over what is accessible to concepts highlights the limitations of a Hegelian approach to music's relationship to selfconsciousness.

Now it is clear that feelings are themselves historically mediated, and that what counts as music changes with history. This does not, though, affect the argument that a Hegelian model lacks the essential dimension which the Romantics discuss in terms of their notion of feeling. ${ }^{8}$ The point about feeling is that it is not reducible to the ways it comes to be understood because it need not become conceptual, being susceptible to kinds of articulation which do not involve the generality of verbal language. The significance of this idea depends on understanding the historical circumstances in which it originates. The rise of the idea of musical autonomy and the concomitant emergence of non-representational conceptions of language suggest ways in which more diverse and differentiated forms of world disclosure emerge in modernity via the decline of dogmatic metaphysics. This decline is, once more, two-edged. It opens new horizons, but it also gives rise to a sense that something important has been lost, namely a way of sometimes being in harmony with the rest of the world, despite all the pain and division encountered in it. It is therefore not surprising that the idea of a non-representational, non-conceptual medium being able both to communicate the irreducibility of self-consciousness to the increasingly differentiated results of the activity of the understanding and to offer an 
affective reconciliation with transience occurs to more than one thinker in this period. Music's distinctive ability to convey aspects of our being in the world appears as a crucial compensation in the face of scientific accounts of what we are which become harder and harder to integrate with our experience of the inherently feeling-imbued life-world and our existential sense of transience.

This attribution of philosophical import to music in Hegel's time also relates to music's apparent proximity to 'nature', another concept which involves an often highly problematic - sense of immediacy. Nature should be understood here, not in Kant's 'formal' sense, as what is bound by necessary laws, but in the sense of the Critique of Fudgement, as what is not reducible to being understood in conceptual terms. Nature in this sense is most obviously manifest in pain and pleasure. ${ }^{9}$ Hegel relates music to 'primitive' expressions, such as birdsong or wordless cries, but, as Schleiermacher also insists, for something to be music it requires more than what is present in non-human nature: 'For neither the expression of a momentary sensation by a . . . speechless natural sound, nor speaking which approaches song are music, but are only the transition to it' (Schleiermacher 1931 p. 369). Music for Schleiermacher is only music if it conveys 'movements of self-consciousness, to the extent that they are not ideas [i.e. not propositional], but real states of life' (p. 394). It is this status in between the 'natural' and the conceptual which makes music so instructive in the present context.

What music conveys is neither wholly mediated in the manner of inferentially articulated conceptual knowledge, nor immediate in the manner of raw feeling, and this can also, as we saw in Schleiermacher, be said of certain aspects of language. For Hegel the transformation of natural sounds into music is analogous to the representation in a painting of a natural scene which reveals more than would be revealed by the contemplation of the scene unmediated by art. Music, like the concept which reveals the higher truth of sensuous immediacy, has to bring 'feelings into determinate relations of notes' and to 'take the natural expression out of its wildness, its raw state, and moderate it' (Hegel 1965 II p. 273). What, though, does philosophy then do with music, apart from try to suggest the need to overcome it in turn, in the name of the higher forms of articulation upon which conceptual knowledge of the objective natural and social world relies? It is this kind of Aufhebung which certain thinkers in this period think music resists.

E.T.A. Hoffmann's famous review of Beethoven's Fifth Symphony in 1810 offers an extravagant version of what I mean: 'Music opens up an unknown realm to man; a world that has nothing in common with the surrounding external world of the senses and in which he leaves behind all feelings which are determinable by concepts in order to devote himself to the unsayable' (Dahlhaus and Zimmermann 1978 p. 197). Hoffmann, it should be remembered, is both a talented composer, and a more than competent musicologist, as the rest of his review of Beethoven's symphony shows. Both Hegel and Hoffmann share a metaphysical suspicion of the 'external world of the senses'. 
Their reasons for the suspicion are, though, very different. For Hegel the truth of music is eminently sayable in the form of philosophy, which is able to grasp the truth of the outer world of the senses while overcoming its transience. As we saw, he maintained that the 'Unsayable, emotion, feeling is not the most excellent, the most true, but rather the most insignificant, most untrue' (Hegel 1959 p. 56). For Hoffmann music can, in contrast, articulate the 'unsayable', which is not representable in language and is based on 'feeling'. Writing about Beethoven's Op. 70 piano trios in 1813, he suggests that 'in the midst of this unlocked realm of spirits the delighted soul listens to the unknown language and understands all the most secret intimations by which it is seized' (Hoffmann 1988 p. 121). The difficulty of sustaining this position becomes apparent, however, in his essay 'Old and New Church Music' (1814). Hoffmann here presents the conception of music as the means of access to a realm beyond the sensuous, not, as he did in the Beethoven pieces, in terms of wordless instrumental music that is free of the compulsion to relate to what words may say, but instead in terms of the church music tradition deriving from Palestrina, which relies on the setting of liturgical texts. The inconsistency between these positions could only be overcome by making a substantial link between what is 'said' by wordless music and the content of liturgy.

Hoffmann's defensible point is that music discloses dimensions of self and world which verbal language alone cannot disclose. He gets into difficulty because he makes the same sort of metaphysical claim about music as Hegel makes about philosophy. The instructive problem for Hegel lies in the connection between language and music. He actually describes music in a way which many contemporary thinkers would now see as applying to verbal language: 'the notes are in themselves a totality of differences, which can divide themselves and combine themselves into the most multiple kinds of direct consonances, essential oppositions, contradictions and mediations' (Hegel 1965 II p. 273). We have already considered the idea of the totality in which the determinacy of each element depends on the other elements in the analogies of music to the Logic. The same conception recurs, no doubt via the influence of the thought of the Idealist and Romantic traditions, in Saussure's account of language. Schleiermacher had already shown that there are no concepts independent of linguistic articulation. Saussure drives home the point that, instead of pre-existing ideas being represented by words, the opposite is in fact the case. Ideas themselves depend on the differential articulation of the material of the signifier, whether the signifier be material marks or moving sound waves. The specific material itself is not central to the constitution of meaning: it is the relationships between the elements that count, not anything inherent in the particular element. ${ }^{10}$ Because meaning is independent of the specific form of existence of the signifier, it seems that it must be grounded in 'nothing', the difference between signifiers, and this opens up a vital connection to music. When enjoined to 'taste the difference' between $a$ and $b$, one can only first taste $a$ and then $b$ : this therefore entails what is itself neither $a$ nor $b$. The subject would seem to 
be located here, as the locus of the relations between linguistic, musical, gustatory and other moments. In order to be such a locus the subject requires the existential continuity Schleiermacher termed 'immediate self-consciousness'.

The structuralist view of differentiality derived from Saussure has come to be seen as a way of questioning the metaphysical division between thought and the manifestation of thought in language, and such questioning is common to various traditions in contemporary philosophy, connecting such differing thinkers as Derrida and Sellars (see Wheeler 2000). Schelling's version of the issue of differentiality already pointed the way, as we saw in the comparison with Derrida in Chapter 4, to contemporary questioning of metaphysics (while also suggesting problems in some of that questioning). How, then, does Hegel fit into these versions of the idea of language, music and difference? For Hegel, the relationship between determinate content in music and the text which can make it determinate seems to reduce the former to the latter, as the former has, at best, a deficient kind of determinacy. Is this account, though, able to do justice, for example, to those Schumann songs, such as the last song of Dichterliebe, in which, after the words cease, the solo piano comments on what has been said? Were the text to continue at this point, the power of what the song 'says' would be greatly diminished. Particularly in the final song of the cycle the piano postlude comes at precisely the point when words are no longer any use for the evocation of what the poet is enduring. ${ }^{11}$ How, then, can we give an account which does justice both to Hegel's insights and to the dimensions he neglects?

What links language and music here is the fact that linguistic elements can only become meaning-bearers within the context of other elements, and notes can only become musical notes, rather than physical frequencies, within the context of other notes and in relation to a subject that hears them as music. ${ }^{12}$ In both cases forms of articulation which can enable us to understand more of and orient ourselves in the world, and which can therefore themselves be understood, share a related structure. Furthermore, each form is able to do things the other cannot, and some aspects of each seem to be very closely analogous to aspects of the other. Rorty talks of people like himself 'for whom language is a tool rather than a medium, and for whom a concept is just the regular use of a mark or noise' (Rorty 1991 p. 126). In these too reductive terms there can actually be no essential difference between music and language, the one being able to be a tool for what the other may not achieve, and both relying on repeated use of certain noises. Leaving apart the question of what makes it clear that a mark or noise is really being used to mean something, which seems to demand an account of the subject, the fact is that Rorty's approach does too little to elucidate why the relationship between music and language became such an issue at the time of the emergence of the non-representationalist conceptions of language upon which his pragmatism relies.

For Hegel to argue as he does, at least in relation to music, he has to think of verbal language in representationalist terms, not as a tool in the pragmatist sense, and this, I think, is another of the reasons why he cannot be co-opted as 
readily into their canon as some of his contemporary pragmatist advocates would wish. Schleiermacher's hermeneutics, in contrast, regarded the aspects of language that are resistant to conceptual articulation, not as contingent additions, but as constitutive elements of language. His attention to the 'musical', language as sound and dynamic transition, was based upon his understanding of immediate self-consciousness. The epistemological justification of this notion becomes apparent when considering Hegel's account of the relationship of language to the I. The problem with the way Hegel discussed the signifier ' $\mathrm{I}$ ' in the Encyclopedia was, as we saw, that the structure of reflection failed to give a criterion of self-identification for the I. As Derrida has suggested, and here he moves close to the critiques of reflection we have examined from Fichte onwards, the determinacy of the linguistic mirror in which I reflect myself - the signifier ' $\mathrm{I}$ ' - itself depends on its relations to other signifiers, which means that it can never be finally determinate. As Frank points out, Derrida seems to offer no account of self-consciousness at all, rather than seeking an alternative to the model of self-presence via reflection in the other of language. In order to escape precisely this problem Schleiermacher insists, as we saw, that there is a noninferential dimension of the self which is not fully articulable by our propositional descriptions, without which inferentially based self-identification can make no sense. The inaccessibility of this aspect of ourselves to what can be determinately said - truth-determinate utterances relying on sharable inferential grounds - leads Schleiermacher to the idea that it is only by circumventing language's universalising function that 'feeling' and individuality could be made manifest. What Schleiermacher means by the 'musical' is an aspect of this kind of use of language, which articulates or shows something beyond what can be determinately said. When looked at in this perspective Hegel's description of music as a 'totality of differences' means music is actually less easy to distinguish from language than he claims.

The central issue here is what deconstruction, in the wake of Heidegger, calls the 'metaphysics of presence'. What the term refers to is exemplified in Hegel's account of language in the Phenomenology. Derrida has characterised what he means by metaphysics as 'presence' in terms of reflexive 'hearing oneself speaking', and this idea is apparent in Hegel's comments, in which the individual subject hears itself speaking via the language it shares with other subjects. Hegel describes language as

the existence of Geist. It is self-consciousness which is for others, which is immediately present as such and is as this general [self-consciousness]. It is the self which separates itself from itself, which as pure I = I becomes objective to itself, receives itself in this objectivity equally as this self, as it flows together directly with the others and is their self-consciousness. (Hegel 1970 pp. 478-9)

The equivalence between the individual self and others comes about via the assumption of semantic symmetry between self and other. However, it is precisely the notion of meaning as something universally shared by, and identical 
between, self and other which falls prey to the questions concerning meaning that we considered in Schleiermacher. He held such a notion of meaning to be a regulative idea for interpretation of and interaction with the other, not something whose existence could be assumed or proved. Furthermore, Hegel's account also fails to deal with the fact that the self-presence which is supposed to result from becoming other through language cannot anyway be attained in these terms. For the reasons we have just seen, if one is to be able to designate oneself with the signifier I, one cannot rely solely on the shared, general structure of Geist manifested in language.

Friedrich Schlegel's claims about the relationship between music and feeling cited in Chapter 1 show one way of connecting this issue to music:

Now if feeling is the root of all consciousness, then the direction of language [towards cognition] has the essential deficit that it does not grasp and comprehend feeling deeply enough, only touches its surface ... However large the riches language offers us for our purpose, however much it can be developed and perfected as a means of representation and communication, this essential imperfection must be overcome in another manner, and communication and representation must be added to; and this happens through music. (Schlegel 1964 p. 57)

'Representation and communication' do not, Schlegel argues, do justice to the source of what matters to us and thus to our capacity to ascribe and receive significance. This 'root of all consciousness', the ground of significant differentiation, cannot be articulated propositionally: 'Feeling and wishing often go far beyond thinking.' Schlegel therefore talks of 'music as inspiration, as the language of feeling'. The claim that music is 'the only universal language' (p. 57) need, then, not be merely hyperbolic, if one accepts the notion of a language as a form of articulation which can be understood, rather than just as a means of representing the world. Furthermore, the emergence of philosophical concern with the idea of literature at this time, as Schlegel goes on to suggest, is inseparable from music: 'The higher language as well should be music; here literature is the link which connects music and language' (p. 58). Literature connects the two because, like music, it cannot be understood as such in representational terms - as Schleiermacher argued, there can be no concept of a style - and therefore depends on aspects of self-consciousness which are not reducible to reflective, propositional awareness of the kind that are apparent in our understanding of rhythm, tone, mood, and so on. As we have seen, there is always a musical aspect to any use of language, and this aspect is not reducible to language's referential functions.

Importantly, the sort of questions raised by Schlegel can lead in both metaphysical and non-metaphysical directions. They lead in a metaphysical direction if music is taken, as it is by Hoffmann, to furnish what philosophy cannot, namely the means of reconciling freedom and necessity that is manifested by music's saying the unsayable. Hegel's metaphysical argument is, in contrast, that philosophy has to overcome the sensuous, the finite, including the finite in 
music and language, in order to arrive at the realisation of the inherent lack in the finite that takes one from understanding to reason. Against Hegel it can be argued, however, that 'absolute music' may in one sense be able to overcome the finitude inherent in language more effectively than language as Hegel conceives it. What interests many of those who seek positive metaphysical content for music is the fact that music is not bound to the objective world in the way that even the most abstract verbal language is. The word 'abstraction', of course, itself has roots in very concrete human activities. Hegel's attempt to suggest how these roots can ultimately be overcome relies on the idea that everything sensuous negates itself, leading eventually to the point where there is nothing left to negate. Verbal language, though, seems inherently resistant to such a conception.

The metaphysical aim of the purism seen in Hegel is encountered in a variety of guises in modernity. If one assumes language is bound up with the world of objects in a way that makes it impossible for language fully to transcend that world, other less representationally bound forms can be seen as taking on a new significance. Around the beginning of the twentieth century these kinds of ideas are often connected with a 'language crisis', such as the one described in Hofmannsthal's 'A Letter' (1902). Here the arbitrariness of the signifier is understood as threatening to separate language from the world, so that the subject loses any stable contact with the world. Another manifestation of this kind of idea is the desire to express philosophy in a logically purified language that is encountered in the early stages of analytical philosophy. This involves an attempt to transcend the perceived contingent limitations of natural languages. ${ }^{13}$ In Soul and Form (1910), which formulates an aim akin to that of Idealist metaphysics, Georg Lukács similarly wishes to overcome contingency by seeking to 'arrive where everything becomes necessary because everything expresses the essence of man, nothing but that, completely and without residue - where everything becomes symbolic, where everything, as in music, is only what it means and means only what it is' (Lukács 1971 p. 23). Because the relationships in music are internal, music is not bound to the contingent objective world in the ways that verbal forms are. What is sought in a theory like this is precisely a means of establishing a kind of metaphysical presence which the arbitrariness and differential constitution of the signifier make inaccessible to verbal language. The problem is that such theories have to give positive metaphysical content to music by stating in what music's transcendence of concepts consists. The more promising option is to employ music to show how concepts themselves involve elements that are inseparable from music and so cannot wholly absorb the significance of music into themselves. This latter conception points to the non-metaphysical alternative suggested in Schlegel's remarks linking music and the idea of literature, and in Wittgenstein's remarks cited in Chapter 6.

The issue of music here raises an interesting possibility for investigating differing interpretations of the current understanding of the effects of the 
centrality of language on the perception of the tasks of philosophy. In Chapter 6 I contrasted the responses of Lyotard, Davidson and Rorty to the situation in which a grounding of meaning in 'presence' is renounced. Wheeler suggested that the difference in response depended on how far a philosopher thinks 'philosophical notions . . . infect the rest of culture' (Wheeler 2000 p. 71). The nonmetaphysical interpretation of the issues raised by Schlegel results from the idea that regarding the representational aspect of language as merely one limited part of a much larger picture of language as human practice opens up new possibilities and loosens boundaries between language and music. ${ }^{14}$ We have seen in previous chapters how Rorty's contemporary claim that philosophy is really a kind of literature is based on the rejection of the 'metaphysics of presence' involved in representationalist conceptions of language. The consequences for Rorty are a refusal to privilege the kind of discourse philosophy has traditionally been assumed to be, and a concomitant attention to the relationship between the public and private significance of different types of discourse. It is here that some of the most emphatic manifestations of the differing responses to the perceived end of the representationalist paradigm have emerged. Music can, for example, provide an occasion to consider the viability of some influential claims in post-structuralism.

\section{The 'presence' of music}

The extreme response to the consequences of a rejection of representationalism is very apparent in Paul de Man's essay on Derrida, 'The Rhetoric of Blindness'. De Man describes the 'metaphysics of presence' as 'a tradition that defines Western thought in its entirety: the conception of all negativity (non-being) as absence and hence the possibility of an appropriation or a re-appropriation of being (in the form of truth, of authenticity, of nature, etc.) as presence' (de Man 1983 p. 114). De Man's extravagant comment means that the whole of Western thought is supposedly infected by a problem which is really characteristic only of certain kinds of philosophy. His claim is, for example, probably applicable to Hegel's conception of language as the general means via which the individual subject appropriates itself. 'Presence' in Hegel is supposed to be guaranteed by the structure of reflection, by the recognition of the discourse of the other as constitutive of the truth of the self. Both de Man and Derrida think that this conception can be deconstructed, but, as we shall see, they ignore the fact that a non-reflexive model of the self, of the kind we have repeatedly encountered, cannot be characterised in terms of self-presence.

Somewhat ironically, however, de Man's own totalisation of 'Western thought' already deconstructs itself when, in the same essay, he interprets Rousseau, presumably a key representative of 'Western thought', as revoking the notion of presence in certain aspects of his view of music. De Man shows that, in the Essay on the Origin of Languages (1762), Rousseau was aware of the differential constitution of music and its relationship to language: 'With 
remarkable foresight, Rousseau describes music as a pure system of relations that at no point depends on the substantive assertions of presence, be it as a sensation or as a consciousness' (p. 128). What makes a musical sign a sign is, he argues, neither its iterability nor its reference to a 'state of consciousness':

Music does not imitate, for its referent is the negation of its very substance, the sound. Rousseau states this in a remarkable sentence... . 'It is one of the main advantages of the musician to be able to paint things that one could not hear, whereas it is impossible for the painter to represent things you cannot see; and the greatest feat of an art which operates only by movement is to be able to convey by movement the very image of repose' (translation of Rousseau amended). (1983 p. 130)

De Man wishes, then, in opposition to Derrida's interpretation of Rousseau in Of Grammatology (1967), to show that Rousseau's connecting of music and language involves a deconstruction of the 'metaphysics of presence': 'Like music, language is a diachronic system, of relationships ... The structural characteristics of language are exactly the same as those attributed to music: the misleading synchronism of the visual perception which creates a false illusion of presence has to be replaced by a succession of discontinuous moments' (p. 131). De Man's dramatisation of his contentions cannot conceal the fact that what is at issue is basically another version of the attack on the 'myth of the given'. He understands the given in terms of the optical metaphor which takes meaning to be the re-appropriation of something which is already supposedly present as itself. His conception is therefore in line with the pragmatist critique of the idea that our language could be said to latch on to something already given as such in the world. Similar questioning of this idea in Romantic thought allowed music to play a role in re-thinking our understanding of language. It is, though, not clear that one can simply equate verbal language and music, even though there may be no final way of determining the division between the two, not least because neither can be thought of as a natural kind.

The real question here has to do with the consequences that are drawn from the historical changes in the understanding of music in relation to language, and this is where the assessment of modern philosophy's significance for the rest of culture divides responses to the rejection of representationalism. De Man says of Rousseau's conception of the musical sign:

the musical structure obeys an entirely different principle from that of structures resting on a 'full' sign, regardless of whether the sign refers to sensation or a state of consciousness. Not being grounded in any substance, the musical sign can never have any assurance of existence. It can never be identical with itself or with prospective repetitions of itself ... the identities of physics have no bearing on the mode of being of a sign that is, by definition, unaffected by sensory attributes. (pp. 128-9)

The 'full' sign is presumably the sign according to the empiricist conception, in which the sameness of a sensation or state of consciousness is the condition of meaning. This conception was, of course, already rejected by Kant, because intuitions cannot be strictly identical, identity depending instead on judgements 
according to the rules of the understanding, which can always be misapplied in real situations. In the wake of Kant, a hermeneutic conception like that of Schleiermacher rejects the empiricist conception because of the inferential nature of all understanding of utterances. The question in relation to de Man is why he attaches such polemical weight to music's non-representational character when the basic argument can also be used to suggest that thinking of verbal language primarily in representational terms is simply a mistake, albeit one that did dominate a significant part of the history of Western philosophy until the Romantics.

One important aspect of de Man's contentions, which helps explain his stance, is his strong conception of aesthetic autonomy. The relationship between music and language means that 'What is here called language . . . differs entirely from an instrumental means of communication' (p. 131). Art thus becomes constituted by lack of 'plenitude': it cannot be understood in terms of a metaphysics of presence. Presence is linked to instrumentality in a move which has been decisive for the history of aesthetic theory. In contrast to the conceptions encountered in Kant and some of the German Idealists, independence from the sensuous no longer points to the unrepresentable supersensuous, it now points instead to the end of 'metaphysics'.

De Man's conception echoes a whole series of Romantic-influenced accounts of the relationship of art to philosophy, of the kind we have touched on in previous chapters, such as those of Adorno, the later Heidegger, and thinkers like Lyotard. In some respects all these thinkers tend to arrive at a very similar and questionable position. The validity of this position depends first of all upon there being a substantive historical link between the history of metaphysics and the dominance of instrumental reason, so that what happens 'on the ground' can be traced to an origin in a particular, totalised account of the nature of thought. The associated further pre-condition of the validity of the position is the claim that the link between metaphysics and instrumental reason is to be made in terms of the subject as that which has to dominate the other in the name of self-preservation.

However, De Man's own assertion that there is a 'tradition that defines Western thought in its entirety' seems to rely precisely upon the notion of presence that he opposes in the same argument. The claim that all Western thought is defined by the search for presence presupposes what one can only term the presence of all of Western thought if it is to be valid. However, that presupposition offends against de Man's other claims about language and presence, which must allow for an indeterminately diverse number of interpretations of the tradition of Western thought. His way of characterising that tradition is, then, based on the kind of 'appropriation' that de Man himself wishes to reject as metaphysical. As we have seen, though, this totalising - Heideggerian - account of the history of conceptions of the subject is anyway misleading and one-sided. A further problem here is that just because philosophers may often have thought in terms of their texts appropriating the truth, their actual effects on culture 
need not be understood in those terms, nor need the culture in question have functioned in terms of the way philosophers thought. ${ }^{15}$ The contextualist view I have been proposing suggests the need for a much more differentiated historical picture, which does not assimilate history to a disputed history of philosophy. If this view is accepted, the kind of importance attached both to art's non-instrumental character and to the history of metaphysics must be reconsidered. Music provides an ideal illustration of the need for this kind of approach, precisely because, as de Man shows, it helps us to ask vital questions about the nature of language in relation to metaphysics and aesthetics. At the same time, it is important to remember that music is also a form of human practice which signifies in a whole variety of ways that are not directly connected to philosophical questions.

De Man's own account of the relationship of music to language is so extreme that his insights into these questions get obscured. The notorious problems associated with the notion of identity can suggest why. If signs have to be physically embodied they may indeed, as he suggests, never be 'identical', in one strict sense of the word. This was part of the reason why Kant insisted that identifications were instead a result of the activity of judgement, not of the manifold of intuitions given to the subject. Given that judgement itself relies on sensuously instantiated language, thus on signs, there is clearly a problem in explaining how it is, for example, that the occurrence of one speech act can have the same meaning as the same sequence of words being uttered at another time. This has led to a whole series of deconstructive arguments which aim to show that the interpretation of speech acts is perhaps undecidable in the last analysis. At the same time, as Derrida has acknowledged, the iterability without which language could not function at all as language, must involve some idealisation of the sign that allows it to be identifiable with another occurrence of the 'same' sign at a different time. While ruling out any sense in which language is to be understood in representational terms, thus as providing a 'full sign' which would allow definitive interpretation, this does allow at least some basis for being able to argue about the meaning of a word in a context, even if there is no foundational meaning of the word in terms of which its occurrences can be understood.

De Man is, then, for the reasons we have just seen, aware that the identity of a sign cannot be based on its materiality, but what criterion does he have for talking about 'music' at all, if there is no sense in which musical signs can be identical? His claim is based on the fact that musical signs do not have an assignable referent, and are not to be identified in terms of their physical frequencies, as the idea that musical movement is able to convey its opposite suggested. The same can, though, be the case for the use of verbal language. If the notion of correspondence to a ready-made reality is rejected, language comes to be regarded as a tool for a whole variety of purposes, including, as we have seen, saying things that are meaningless in terms of existing expectations about the meaning of a word. ${ }^{16}$ The dramatic consequences de Man wishes to draw from this fact 
depend upon the initial assumption that there is a totalising story to be told about 'Western thought', in which language has only ever been understood in representational terms. These consequences are also a result of the fact that he pays little attention to language as a social practice which can play cognitive, expressive and a series of other roles. In the case of music there must be, however minimally, some kind of identity between differing cases of this form of articulation, which would enable them to be regarded as musical signs, even if this identity is historically shifting. ${ }^{17}$ This identity can, for example, be thought of in terms of shifting social consensuses about the appropriate employment of such terms as music. The further point here is one we encountered in relation to Schelling and Derrida: difference must relate to something which remains the same, for it to be difference at all. Schleiermacher's notion of immediate selfconsciousness, which he claimed was essential to thinking about music, provided the existential continuity without which the sustaining and changing of social patterns of difference and identity becomes incomprehensible. The further epistemological point about immediate self-consciousness was that it avoided the problems of reflection.

Now both De Man and Derrida reject, in much the same way, the reflection model of consciousness. Derrida does this, however, in a manner which leads him at one point to what Manfred Frank aptly refers to as a 'Hoffmann-esque Nachtstück'. At his most pessimistic, Hoffmann's worries about self-knowledge, of the kind encountered in the figure of the Doppelgänger, mean that the split within the self required to arrive at self-knowledge provides no ontological stability for the self: the other does not reflect a familiar self back to one. For Hoffmann music is able to provide a way out of this dilemma because it revealed a way in which self-consciousness could harmonise with itself while engaging with something beyond itself. ${ }^{18}$ We have already seen why the idea of selfreflection in the signifier could not explain self-consciousness. Derrida characterises consciousness' relationship to language with the metaphor of a mirror without a tain, which reflects an uncontrollable alterity back to it - precisely the Romantic nightmare encountered in the figure of the Doppelgänger. The unstable other which does not reflect one back to oneself is what de Man characterises by the notion of the empty sign which precludes full presence. Derrida moves from the tain-less mirror to the paranoid fantasy that 'A language preceded my presence to myself . . . a sentence was waiting for "you", is looking at you, is watching over you' (cited in Frank 1989 p. 807) as a description of subjectivity's relationship to language. The problem is that in his desire to avoid any sense that the subject could be 'self-present' - that would raise all the problems of reflection - Derrida transfers attributes of self-consciousness into language. His language that waits, looks and watches leaves one with the problem of how differential articulations can wait, look, pay attention, let alone hear something as music. The idea that these may be attributes of a consciousness that cannot be theorised in terms of reflection seems, as Frank shows (p. 811), not to have occurred to him. One cannot characterise subjectivity in terms of self-presence, 
but that does not obviate the need to acknowledge its role in the functioning of systems of articulation.

The subject in this sense is what allowed differences to become manifest as differences, and thus to make meaning possible. As Brandom argued, the mere registering of difference is, to use Schleiermacher's term, 'mechanisable': a computer can do it. What is at issue here is the difference between the mere registering of $x$ as not $y$, and the registering of $x$ as conceptually or affectively significant to someone, the latter being the reason for developing more varied ways of carrying out the former. Why would we bother to distinguish things in ever more complex ways if they did not already matter to us? As we saw, Kant claimed that although cognition is now divorced from pleasure it must previously have been connected to pleasure, 'and only because the most common experience would not be possible without it did it gradually mix with simple cognition and was no longer particularly noticed any more' $(C \mathcal{F}, \mathrm{B}$ p. XL, A p. XXXVIII). The same kind of synthesis as is required to make a cognitive judgement is required to hear different notes as part of a piece of music, thus suggesting links between the cognitive and the affective. Frank suggests that the 'musicality' of language in poetry, which depends upon the rhythm and sound of language, cannot be adequately explained by the assumption that there are two dimensions of language, the poetic and the referential: 'For if according to Saussure - a language only consists of differences, and if, furthermore, the differences are unsayable, then one can justifiably claim that the unsayable is the ground of the sayable' (Frank 1984 p. 601). The significance of the repetition of a word in a text is, for example, not inherent in the word repeated, but rather in the transition from the same, to the different, back to the 'same' which now has a different significance. That difference is a difference to a subject that exists between the two moments of articulation and can invest their connection with a feeling of significance. The same kind of feeling is at issue in the repetitions in music. The subject's relationship to language is, then, 'unsayable', because saying something meaningful always also depends upon what cannot appear in the saying itself, namely what connects the temporalised, differentiated moments of the utterance and can form and develop itself via those connections.

Far from the musical sign being most apt as a means of deconstructing the notion of constitutive, instrumental subjectivity, then, it points instead to dimensions of communication which make possible a different understanding of subjectivity and language in modernity. Oliver Sacks tells how recognising aphasia can be very difficult, to the point where a computerised voice synthesiser is required, because the patient would otherwise use all sorts of extraverbal affective cues to understand what is being said: 'With the most sensitive patients, it was only with such grossly artificial mechanical speech ... that one could be wholly sure of their aphasia' (Sacks 1986 p. 77). These patients have, tragically, lost something essential, but 
something has come in its stead, has been immensely enhanced, so that - at least with emotionally laden utterance - the meaning may be fully grasped even when every word is missed. This, in our species, Homo loquens, seems almost an inversion of the usual order of things: an inversion, and perhaps a reversion too, to something more primitive and elemental. (p. 77)

Despite tending towards that side of Rousseau which invokes a pre-lapsarian state, which Derrida unmasks in Of Grammatology, Sacks does suggest ways in which language in modernity can involve more than just the primary repression associated with the insertion into the symbolic order that is suggested in Derrida's remarks about 'the sentence'. The mechanisable side of language can involve a repression of other vital dimensions of experience, but music can help to articulate these dimensions, and this points to a very different account of the subject's relationship to language.

In Proust's The Captive the narrator says the following on hearing the Vinteuil sextet:

And, just as certain creatures are the last surviving testimony to a form of life which nature has discarded, I wondered whether music might not be the unique example of what might have been - if the invention of language, the formation of words, the analysis of ideas had not intervened - the means of communication between souls. It is like a possibility that has come to nothing; humanity has developed along other lines, those of spoken and written language. (Proust 1981 p. 260)

The pre-lapsarianism in this passage can obscure its real significance, which lies in what it says about the perception of language in the modern period. The passage echoes ideas originating in Romanticism. Novalis, for example, ponders the idea of a 'purely poetic language' with no determinate meaning, and claims that for the poet 'words are not universal signs - they are notes - magic words which move beautiful groups around themselves . . . for the poet language is never too poor but always too universal' (Novalis 1978 p. 322). Similarly, the Symbolists attempt to write 'absolute poetry' as a means of renewing a language which is seen as increasingly subject to the instrumental imperatives linked to the universalisation required for modern rationality. The metaphysical idea of music as a form of language which achieves something that is lost to representational verbal language has been a powerful impetus behind many aspects of aesthetic modernism. The important thing is to understand this idea in a sufficiently differentiated manner.

If music is understood in relation to de Man's idea that all Western thought has been the failed attempt at 'an appropriation or a re-appropriation of being', it can easily come to be regarded as a straightforward substitute for that philosophical failure. This then connects music to other ways of attempting to deconstruct the metaphysics of presence. The problem is that de Man himself relies on just as absolute a claim for his account of the significance of music as what he opposes, as if the history of metaphysics were really a unified entity, rather than a never fully denominable collection of texts and their past and future 
interpretations and effects. An even bigger problem, perhaps, is de Man's account of the subject, which ignores the questions regarding its relation to music of the kind that have concerned us in the present book. It consequently becomes difficult in his terms to understand why music should have been the source of some of the greatest cultural triumphs in the modern period. Now it $i s$ arguable that instrumental language, the language of the 'subject', in the sense of that which dominates its other, does increasingly colonise many forms of modern social existence, as Heidegger, Adorno and others claim. What such an argument can too easily exclude, however, are the aspects of subjectivity which have nothing to do with domination.

It is here that the potential of music for helping to sustain a different conception of the subject becomes crucial. If the subject is not transparent to itself, as the arguments for immediate self-consciousness suggest, it is inherently divided between what it is and what it knows of itself, and these can never finally coincide. The history of the subject in modernity can therefore also be characterised in terms of the subject's attempts to come to terms with the divisions which constitute it, as Hölderlin already suggested. One way of trying to get beyond such divisions is precisely to resist the ways in which language can become reifying, by seeking to circumvent its instrumental use, and the desire to do this is a crucial aspect of modernism in all the arts. This desire is one of the main sources of the idea of aesthetic autonomy, which is inseparable from the changes in the status of music at the end of the eighteenth century, and from the connection of these changes to the rise of the modern conception of literature. A decisive aspect of this conception is that the reduction of language to semantic determinacy is viewed with suspicion, as being capable of obscuring aspects of the world which other forms of articulation can reveal. This is why the 'birth of deconstruction out of the spirit of music' suggested by de Man's remarks can be linked to early Romantic philosophy, which sometimes talks of music in ways which are analogous to the way deconstruction discusses texts. In this perspective the remarkable popularity of deconstructive reading, especially in the United States, can be seen in some respects as a further aspect of the history of Romantic thought. The main differences between these recent approaches and Romantic thought lie, though, in their account of subjectivity and in the assumptions about the consequences of the rejection of representationalism for conceptions of modernity. Here we need to take another look at aspects of Romantic thought in relation to recent theory.

\section{'Infinite reflection' and music}

In the section of the Aesthetics on 'Irony' Hegel argues that Friedrich Schlegel's notion of irony is a result of Schlegel's Fichtean notion of the I, which posits the non-I: 'What is is only through the I and what is through me can just as much be destroyed by me again', so that everything is regarded as 'produced by the subjectivity of the I' (Hegel 1965 I p. 72). The echoes of Hegel's remarks 
about music should be clear: music was limited because it is subjectivity 'resting in unbounded freedom solely upon itself'. The freedom of Fichte's I is, Hegel maintains, completely abstract, and this, he thinks, leads Schlegel to the idea of living one's existence 'artistically'. All that the I produces is solely 'appearance', lacking the 'seriousness' that results from engagement with objective social reality. This lack of seriousness means any product of the subject can easily be dissolved by an all-consuming irony. There is, therefore, for Schlegel, no investment in subjectivity transcending itself into the objectivity which would result from the encounter with other subjects. These claims mirror Hegel's concern that music fails to objectify itself either in the form of determinate objects or ideas. The puzzling side of music without a text for the expert, which made it 'capable ... of the most various interpretations', is, then, also present in Hegel's negative view of the implications of early German Romantic notions of irony. Hegel, of course, sounds here more than a little like many contemporary critics of deconstruction.

Subsequent research (see the discussion of Benjamin below, and Frank 1997) has made it clear how far Schlegel had already moved away from his attachment to Fichte by 1796, so Hegel's judgement is already problematic in this respect. Schlegel's irony is really a result of his rejection of the Idealist assumption that philosophy could constitute a complete system based on the positing of the subject. Romantic irony requires the negation of an assertion, but, unlike the familiar rhetorical trope, not in favour of a determinate contrary assertion, because that assertion will be equally partial and incomplete. Hegel actually adopts a similar idea in his notion of the negation of the negation, but at the end of his system he abolishes the ironic, transient status of its particular elements in the way we have seen. It should be apparent from the difference between the two why Schlegel might come to seem close to aspects of post-structuralism. Post-structuralism adopts many Hegelian moves devoted to the avoidance of giving the subject a grounding status, but rejects the closure of the system (see Frank 1984). A consideration of a few aspects of how early Romanticism regarded music can help to clarify the relationship between the attention to undecidability of meaning in Romanticism and in deconstruction, and can also help to assess the aptness of Hegel's judgement on Schlegel's position.

Schlegel makes it evident how important he finds music in the 'Literary Notes' (1798): 'beauty (harmony) is the essence of music, the highest of all arts. It is the most general [art]. Every art has musical principles and when it is completed it becomes itself music. This is even true of philosophy and thus also, of course, of literature [Poesie], perhaps also of life. Love is music - it is something higher than art (Schlegel 1980 p. 151). This piece of apparently shameless hyperbole can make sense if we look at some more early Romantic claims. Novalis thought music allowed the mind to be 'for short moments in its earthly home' because we are 'indeterminately excited by it', and it is the understanding of this indeterminacy that is decisive. For Hegel indeterminacy is ultimately just the failure to carry out the work of the concept to the point where indeter- 
minacy is revealed as being determinable. Romantic philosophy resists this kind of closure via such notions as irony. Music can indeed, then, as Hegel's comments suggest, be seen as being closely related to irony. How the resistance to closure is assessed depends upon assumptions about the status and role of philosophy. Anything determinate we say about significant music is, for example, always also tinged with the sense that there is a necessary mismatch between it and the music. This can either mean that one concurs with Hegel's position by regarding that mismatch as having to do with music's inadequacy, or it can mean that music is important precisely for either its transcendence of or revelations of the limits of the sayable. A version of the difference between an Idealist and a Romantic conception emerges again at this point, and we need now further to elucidate the Romantic conception.

The key secondary work for the difficult question of the Romantics' relationship to Fichte remains Walter Benjamin's The Concept of Art-Critique in German Romanticism (1919). Although subsequent research has revealed much about the early Romantics that Benjamin could not have known, his approach is still valid in many of its essential outlines. Benjamin, like Hegel, regards Fichte as the figure behind the development of early Romantic thinking. Fichte's insistence upon the irreducibility of the subject to objectivity led, as we saw, to a new kind of exploration of the nature of consciousness. A valid conception of Romanticism, for Benjamin, depends on how one approaches the possibilities of this exploration, and the question of 'reflection', the splitting into related aspects that mediate each other, is central to such a conception.

We have seen how Fichte and the Romantics raised the problem of the regress of reflection that lies in the attempt of consciousness to ground itself as the cognitive principle of philosophy. In order to escape this regress Fichte posits a grounding immediacy of consciousness which does not depend upon reflection: 'Thus Fichte is looking for and finds an attitude of mind in which self-consciousness is already immediately present and does not need first to be summoned by a reflection which is in principle endless' (Benjamin $1980 \mathrm{I}, 1 \mathrm{p}$. 26). The essential principle of Fichte's consciousness is the free action, the Tathandlung (literally 'deed-action'). This ground of reflection cannot itself be available to reflection because it is required for the reflection to take place at all: it must remain unconscious, and therefore external to reflection. For Benjamin the concept of the unconscious is associated with the irrationalist tradition that arises from Schopenhauer's appropriation of Fichte, which leads, as we shall see in Chapter 8, to a monolithic conception of the significance of art as the means for coping with an underlying reality which is otherwise irredeemable. The relation of the early Romantics to such a conception is anything but straightforward, because the immediacy of 'feeling' cannot be reduced to reflection, which seems to keep them in a position similar to that of Fichte. The question is, though, whether any conception can do without the function performed by some kind of immediacy, even though that immediacy plays its role in thoroughly mediated contexts. For the Romantics, feeling and reflection have to 
accompany each other: difference presupposes identity if it is to be known as difference. Use of the notion of feeling therefore does not entail a dogmatic claim about the nature of reality in itself: reflection in Novalis did not 'at any moment step over the critical boundaries of the immanence of consciousness and yet it has explained that not everything is in consciousness' (Frank $1997 \mathrm{p}$. 823). Feeling 'can only be looked at in reflection - the spirit of feeling not there any more' (Novalis 1978 p. 18), but that does not mean it does not exist. The simple point of feeling in this respect is that it points to why these things come to matter at all, which is not explicable in terms of reflection. Why does reflection keep taking place in new ways?

Benjamin does not deal with this aspect of Romantic thought. His main concern is to suggest that the endlessness of reflection need not be regarded, as, for example, Jacobi thought it did, as leading to a regress into the abyss. Understanding reflection as leading to an empty infinite regress, whereby selfconsciousness could never result because the series 'I think I think I . . . etc.' carries on ad infinitum is, Benjamin claims, not the only way to understand reflection. The Romantics, he argues, regard the process of reflection as involving the potential for endless articulation, and thus as being something 'fulfilled'. Hamann had already suggested that the endless reflection inherent in different languages should be regarded in terms of a celebration of the multiplicity of God's creation. For the Romantics, in Benjamin's reading, articulation does not require an immediate foundational point from which to develop. There is, therefore, no 'action' of the kind Fichte regards as the necessary origin of thought, which thought itself cannot articulate. For the Romantics, Benjamin claims, 'reflection is logically prior . . . Only with reflection does the thought emerge that is reflected upon' (p. 39). His claim echoes Hegel, for whom the immediate always already requires the other of itself, determinate thoughts always being necessarily split by reflection, the beginning only being the beginning because of what follows it. Benjamin, though, wants to point to the - nonHegelian - sense in Romanticism that there is no ultimate goal of articulation beyond an endless diversity of reflection, which connects nature, art and language, without the need for an initial self-presence of the subject in terms of which this takes place. In this he echoes Hamann, for whom a grounding of articulation would diminish the capacity to celebrate the divine. Hamann considered music to be the oldest language.

In the light of the argument so far, it is not surprising that Derrida's account of différance resembles Benjamin's arguments about Romanticism. Derrida states in Positions that 'différance is not preceded by the originary and undivided unity' (Derrida 1972a p. 17). The subject is secondary to the movement of differance: 'the subject ... depends upon the system of differences and on the movement of différance . . . it is not present and above all not self-present before différance ... it only constitutes itself by dividing itself' (p. 41). The rejection of the myth of the given is applied to the subject itself so that it has the same status as all aspects of the world, which are only ever accessible in terms of their 
mediation in a language. Such arguments show the problem of any attempt to make the subject a self-present, transparent foundation for knowledge, of the kind sought by the Idealist tradition from Descartes onwards. They are, though, not adequate in relation to the non-reflexive conceptions of the self offered by Novalis and Schleiermacher. For these thinkers the infinity of reflection results from the subject's simultaneous lack of self-presence and need to come to terms with this lack. This means the subject is not an absolute point of beginning, but it does not mean that it is only constituted by dividing itself. The sense of lack that leads to reflection requires something which is already in some way itself for that lack to be felt as its lack. The point is that this account of reflection gives a way of understanding what moves the subject beyond itself into 'endless reflection', something which becomes impossible to understand in merely differential, reflexive terms. Benjamin maintains that Schlegel and Novalis understand 'the endlessness of reflection as a fulfilled endlessness of connection [Zusammenhang, which also means 'context']: in it everything is supposed [to connect] in an endlessly multiple manner' (Benjamin $1980 \mathrm{I}, 1$ p. 26), but this does not explain why this endless multiple connectivity could matter to the subject.

Schlegel ponders the question of foundations in philosophy and suggests:

In relation to every concept and every proof one can again ask for a concept and a proof of the same [concept and proof]. For this reason philosophy must begin in the middle like the epic poem, and it is impossible to present it and add to it piece by piece in such a way that the First would be completely founded and explained for itself from the very start. (Schlegel 1963 p. 518)

This passage denies a foundational status to anything like Fichte's I. The Fichtean I can never be grounded in a stable manner: as Derrida argues, it will always be dependent on an unstable other that prevents it being able to be an absolute foundation. However, one must be careful how this argument is related to conceptions of the I. It is too easy to slip from the rejection of the I as selfpresent absolute foundation to an account which excludes ineliminable aspects of self-consciousness altogether and leads merely to randomised difference. Winfried Menninghaus, who links his interpretation of the Romantics to both Derrida and Benjamin, characterises endless reflection as follows: 'one can say that the whole "Being" of endless reflection consists, as a totality of relation, in the reflectings of all its parts: a decentered continuum of centres of reflection' (Menninghaus 1987 p. 47). Unfortunately this does not make sense. For something to be a 'centre of reflection' it must have a periphery which is not itself. The critique of reflection theory makes it clear that such a centre of reflection would have already to be non-reflexively self-aware for it to be able to define itself against its other and thus to be a centre, as opposed to being merely a moment, of reflection at all. If the 'decentred' centres (?) (elsewhere Menninghaus talks of difference becoming a '(non-absolute) Absolute' (p. 87)) cannot, in some sense, be centres and not peripheries, it is impossible even to 
use the notion of a centre. There would in this case be no difference between centre and periphery, no difference between the computer and the self-conscious being. Menninghaus's interpretation of early Romanticism, and at times Benjamin's, simply relies on another version of the untenable reflection model, which, in the haste to escape any foundational role for subjectivity, ends up with no way of accounting for ineliminable features of awareness and self-awareness. A non-reflexive conception of individual self-consciousness like Schleiermacher's is able to allow that philosophy could not found itself from the very start. This is why he argues for a dialectic which tries to facilitate the admittedly endless, but socially necessary, attempt to come to terms with difference without repressing individuality.

Despite these difficulties, Benjamin's account of endless reflection can be productively linked to both a theory of the work of art and a theory of language which point forward to many of the issues of contemporary literary theory. Benjamin's account comes close to Schelling's contention that artworks can be endlessly interpreted 'as if they contained an infinity of intentions, whereby one can never say whether this infinity lay in the artist himself or just in the work of art' (Schelling I/3 p. 620). The similarity is a result of the fact that in both artworks are seen as not having the status of objects of knowledge. The System of Transcendental Idealism, though, saw art as combining the conscious and the unconscious, and as involving a moment in which time is abolished, so that all reflection ceases. This made it into the 'organ' of an Idealist philosophy, in which identity of subject and object was documented.$^{19}$ Romantic philosophy does not rely on this identity, and instead sees our only sense of this identity in the incompleteness we feel in relation to our ability to grasp art. The artwork is therefore inherently temporal, consisting in a potentially endless series of 'reflections'. These reflections occur both in those who engage with the work and via the work's relations to other works of art from the past and the future. Something like what is meant here is the theme of Borges's story about the nineteenth-century author of Don Quixote, Pierre Menard, whose text is richer than that of its original creator, Cervantes, even though the texts are actually identical. In the famous Athenäum Fragment 116, Schlegel claims that the 'romantic work of literature [Dichtart] is still in a process of becoming; yes, that is its real essence, that it can eternally only become, can never be completed. It cannot be exhausted by any theory' and that the work of art multiplies itself 'as if in an endless row of mirrors' (Schlegel 19882 p. 115). The 'mirrors' can, then, be individuals who can never exhaust the work of art, but who also contribute to its mode of existence as a dynamic entity, and they can also be other works which change its significance, in the way that Don Quixote is, for example, changed by its reflection in the work of Symbolist poets.

These issues relate closely to the changing status of music in Schlegel's period, and this also helps generate the kind of conception of literature we observed in Foucault. In Positions Derrida emphasises how important the emergence of the notion of 'literarity', which he sees mainly as an achievement of 
Russian Formalism, is to his project of deconstruction. The notion of literarity enables one, he argues, to avoid reducing texts to thematic, sociologistic, historicist, or psychologistic readings, and it forces one to see how philosophical writing is never 'purely philosophical' because of the metaphorical excess which language always generates. How, though, does this awareness of the nature of literary discourse emerge historically? The fact is that without the growth in the importance of instrumental music the theories being discussed here are much less easy to account for. Consider Schlegel's initiation of the notion of a 'musical idea' in the Athenäum Fragments:

Many people find it strange and ridiculous if musicians talk about the thoughts in their compositions; and often it can happen that one sees that they have more thoughts in their music than about it. But those who have a sense for the wonderful affinities of all arts and sciences will at least not look at the matter from the flat viewpoint of so-called naturalness, according to which music is only supposed to be the language of feeling, they will in fact not find it per se impossible that there is a certain tendency of all pure instrumental music towards philosophy. Must pure instrumental music not create a text for itself? and is the theme in it not as developed, confirmed, varied and contrasted as the object of meditation in a sequence of philosophical ideas? (Schlegel 19882 p. 155)

This passage, more than almost any other, gives the lie to the notion of Romanticism as being initiated by an obsession with the expression of feeling. It is not that Schlegel would deny the importance of feeling, but the elevated role he gives to music makes it clear that his real interest is in new forms of articulation which integrate different cognitive and affective aspects of existence, not in 'self-expression'. Schlegel's polemic is directed in favour of the kind of conception of language we have been concerned with, not of a 'Fichtean' sense of self. Like Schleiermacher (and Hölderlin, Novalis and Schelling), Schlegel simply does not fit into the reductive Heideggerian story of Western metaphysics that regards it as linked to the domination of the subject. The Romantic view does not rely on a representational conception of language, and at the same time keeps a plausible role for the subject in understanding vital aspects of modernity. One key to these positions is precisely music.

Pure instrumental music's 'tendency towards philosophy' derives from the non-representational aspect of wordless music: both philosophy and music are concerned with what transcends the sayable. This transcendence creates a further link with the notion of literature which develops at this time. As we have seen, the notion of the unsayable need not be conceived of mystically: it relates to what happens in language that is not explicable solely in semantic terms, and was suggested in Wittgenstein's remarks about understanding a poem. Schlegel's idea becomes clearer when he refers to Kant's repetition of ideas as making his texts 'musical enough', and to Kant's 'musical repetition of the same theme'. The point is that saying the same thing repeatedly changes the effect of what is said, a fact which is crucial in music. When Beethoven repeats a phrase over and over in the Scherzo of the String Quartet Op. 135, he reveals the way 
that musical repetition can easily tip over into something bordering on madness. The same device which structures much of Beethoven's work can, then, also threaten its very existence as meaningful articulation. Once again the crucial factor here is the subject who apprehends the disturbance to a received order, even though what can be said about this disturbance differs from the actual experience of hearing the piece. This kind of possibility also occurs in texts which come to be regarded as literary because their effects do not derive from their propositional content. It is not, though, as Foucault and De Man implied, that language therefore becomes something purely self-referential, in the form of Literature, the dialectical other of the science of language. Their idea relies too heavily on the claim that language in modernity is tied to instrumentality and that a wholly other sense of language is therefore required to escape this situation. Schlegel's conception is directed rather towards the importance of creating differing forms of articulation which may overcome the limitations of other forms. Strangely, it was Schlegel whom Foucault saw as one of the initiators of the science of language in this period. There is no doubt that Schlegel did help initiate modern linguistics - and modern philology - but he did so as part of a vision which evidently includes the issues that Foucault raises. The main problem with Foucault's account is that it makes the genesis of the notion of literary autonomy too separate from the aesthetic praxis of the time.

Foucault claims the separation of literary language from the 'discourse of ideas' is the key change in this period. This claim becomes more plausible if it is connected to music in the way suggested here, but the sort of separation Foucault intends misses much of the point of the Romantic position. Music is inextricably linked to the emergence both of aesthetic autonomy and of the modern idea of literature. Schlegel says of the novel: 'The method of the novel is that of instrumental music. In the novel even the characters may be treated as arbitrarily as music treats its theme' (Schlegel 1980 p. 146). In the famous review of Goethe's Wilhelm Meister Schlegel claims that: 'The second book begins by repeating musically the results of the first', and that 'This harmony of dissonances is even more beautiful than the music with which the first book ended.' The changed perception of the non-representational character of wordless music becomes a model for the other arts. This is what lies behind Benjamin's claims about Romanticism and reflection: music generates significance by the internal, non-semantic relationships between its elements, though these also relate beyond themselves to the social and historical world. Similarly, instead of characters and events being the 'final purpose' of the novel, such that the novel would be seen as 'representing' a world in the way, say, a newspaper or history book can be said to do, Goethe's novel is a book 'which one can only learn to understand out of itself', which is an internally self-reflecting structure (Schlegel 19882 pp. 159-61). Any part of the text will have a different significance if seen in relation to any other part. This does not preclude reading such a text in representational terms - one can reflect the text in the history of its time - but that is only one kind of reflection. If this kind becomes exclusive, 
one loses precisely what makes the text into what Benjamin calls a 'medium of reflection'.

In his Monologue (1798), Novalis writes of the 'musical spirit of language' in similar terms to the way Schlegel characterises the novel and music. At the same time he makes a further link to mathematics. For both Novalis and Schlegel the idea of representation becomes secondary to the idea of languages as possibilities for world making. This is what makes possible the link between music and literature:

One can only be amazed at the ridiculous mistake, that people think they speak for the sake of things ... If one could only make people understand that with language it is as with mathematical formulae - They constitute their own world - They only play with themselves, express nothing but their wonderful nature, and this is why they are so expressive - precisely for this reason does the strange game of relations of things reflect itself in them. Only via their freedom are they members of nature. (Novalis 1978 p. 438)

The reconciliation of nature and freedom sought by Idealist philosophy is seen not in terms of the establishment of a closed philosophical system, but in the endless creation of new relations between things which give rise to new revelations that is possible in literature and music.

Romanticism has too often been understood as merely revelling in indeterminacy. At this time the sense of liberation via the escape from established kinds of determinacy clearly does dominate the Romantic conception. However, it is important to remember that the freedom from determinacy inherent in music does not turn out to be an arbitrary freedom. The reflection of the 'game of relations of things' in music is, of course, one of the keys to understanding the move of music, from the attempts of Classical and Romantic symphonies to achieve something like the aims of Idealist philosophy in works which integrate more and more diverse material into a harmonically end-directed form, to free atonality, which employs relations that are not given in the harmonic system and which leads to deep problems concerning how to organise works and concerning their reception. Similar issues inform the development of literature that leads to Mallarmé and beyond, in which the gain in freedom generated by the move away from representation also generates ever greater problems in deciding how to write texts that live up to the most stringent aesthetic demands. These inner-aesthetic questions are also an indication of extra-aesthetic matters.

Modernity simultaneously generates systematic determination of more and more areas of life, and the awareness that such determination involves inescapable repressions. The reception of art can therefore turn into a battle between those wishing to fix signification, be it by historical research, attention to the life of the artist, computer analysis of texts, scores, and so on, and those, like the Romantics, who see such an enterprise as inimical to the nature of art, and demand attention to the capacity of art for generating ever new significances. ${ }^{20}$ 
Deconstruction would, in this view, be another version of Romanticism's questioning of the legitimacy of an Enlightenment which sees its task as the conceptual ordering of reality. The danger of this side of 'Romanticism' can lie in the tendency to elevate the demonstration of the limitations of determination to being the main aim of philosophical thought. The concern to avoid 'foreclosure', to avoid arresting the 'play' of différance, must, though, at some point be legitimated as part of the practice of cultural communication and expression. The legitimacy of the work of the early Romantics derived from their showing up the possible repressive effects both of the new attempts to establish a foundational philosophy and of the growing separation of the sciences from the lifeworld. In order to achieve this they needed not only to show how difference could not always be foreclosed, but also to show why this mattered in terms of a new conception of the subject's role in an increasingly system-determined world.

The contemporary return of related ideas derives both from the perceived failure of foundational accounts of language and meaning in philosophy, accounts which derived from the - sometimes too - close links that develop between analytical philosophy and the natural sciences, and from the much more general tendency in modernity for there to be a movement from times where the desire for order prevails, to times where order is perceived as stifling. This latter point is not an abstract one: an effective critical approach to these issues needs to look at how they have manifested themselves in differing historical circumstances. As we shall see in Chapter 8, for example, similar ideas to those of the Romantics are mobilised to very different ends by Nietzsche. Similarly, the debates about the function of art in the face of fascism, which led Walter Benjamin to adopt reductive views for reasons of political responsibility in the later $1930 \mathrm{~s}$, make it clear that these issues are primarily to do with how the real cultural world functions in relation to the challenges of modernity. At some point the 'infinite reflection' in the work of art has to be seen in relation to real people who engage with that work: lives are not lived merely by deferral and art is not ultimately a theoretical matter.

In the case of the Romantics, the historical shift that leads to the conceptions of language and music at issue here involves a motivation that does not derive solely from texts and works themselves. The difficulty of telling this kind of history is that it involves the history of something which is in one sense always absent, namely 'the subject' - remember Schelling's remarks on the fact that the subject can only find 'the monuments, the memorials of that path, not the path itself' of its own history. The connections between the rise of the idea of absolute music and the emergence of radical ideas about art and interpretation of the kind suggested in the notion of infinite reflection are 'monuments' of this history, but they do not give direct access to it. At the moment when, as is most evident in Fichte, subjectivity becomes the principle concern of philosophy, potentials of the subject which were previously unarticulated emerge, along with the realisation of the potential boundlessness of what this may mean. The 
theory and praxis of music is the area in which this realisation is most evidently manifested, precisely because music offers a series of monuments which speak in a way verbal monuments can only do when they move towards music in the form of radical literature.

Connecting this kind of history to other histories involves problems that have rarely been satisfactorily dealt with in the history of ideas. The history of subjectivity articulated in aesthetic theory cannot be told in solely conceptual terms. What aesthetics can say theoretically relies on what is shown and disclosed in a non-theoretical manner in the arts. This does not mean that we therefore descend into meaningless immediacy, but the nature of aesthetic understanding is such that at some point conceptually expressed justifications come to an end and one has to invoke what can only be shown, which may therefore elude one's interlocutors. Whereas in the sphere of knowledge this preparedness to countenance an end to justifications will rightly be considered a dereliction of the duty of justification, in aesthetics this preparedness is germane to the very discipline. Furthermore, it is not that aesthetic issues therefore cease to connect to the politico-social world. This is apparent if one considers that the growth in the importance of music in the German-speaking public sphere in the early nineteenth century is connected to the failure to develop a politically effective public sphere. Much of the energy of Beethoven's music, for example, derives from his admiration for the French Revolution, and to his subsequent feeling of political impotence in the Restoration period. Rudolf Bahro has suggested that the political energy which sometimes appears in Fichte's best writings on freedom, and which elsewhere in Europe led to transformative political action, is only really articulated in Germany in Beethoven's music (Bahro 1979). At the same time, the works of art which help document the history of the subject in Germany should not merely be regarded as the results of a repression. The point of the theory of infinite reflection is that genuine works will continue to signify in a multitude of other ways. Beethoven still speaks so uniquely to those prepared to listen because he suggests a way of being to which we may still aspire, even if history has taught us that it may never be possible to achieve. ${ }^{21}$

The fact remains that many of the questions considered so far in philosophical terms do here also become political questions, and their subsequent history is linked to the unhappy history of Germany in modern Europe. On the one hand, music's growing importance can be associated with political impotence and the concomitant development of 'inwardness', which is evident in Hegel's claim that music involves the subject indulging itself in an abstract freedom which never has to engage with the public political sphere. The failure of this public sphere in modern Germany until after the Second World War is a major source of the disasters of Germany's history, and the contribution to that history of thinking which believes it is possible to withdraw from public action into inwardness cannot be ignored. On the other hand, music can also sustain a potential for new articulation which can provide both individual and collective 
motivations. This is itself a political matter, as the considerable role of music in revolutions from the French revolution to the liberation of South Africa from apartheid suggests. Furthermore, music, unlike the other arts of the time apart from drama, involves collective reception of the kind Schelling regarded as so vital to Greek tragedy. In an anticipation of Wagner, Schelling concludes the Philosophy of Art with reflections on the 'most complete combination of all arts ... which was the drama of antiquity' and wonders if opera, which is merely a 'caricature' of ancient drama, may become able to lead back to 'ancient drama combined with music and song' (Schelling I/5 p. 736). Aspects of Romantic thinking and the music of this period suggest, then, that there is more to the politics of culture than can be encompassed within a Hegelian framework, but these aspects are fraught with danger as well as offering new cultural potential. The case of Wagner will further bring out the inherent tensions between the Hegelian and Romantic conceptions. These tensions will be particularly apparent in Nietzsche's reactions to Wagner and in the exploitation of Wagner by the Nazis.

The route which can be traced from the changes in the understanding of language associated with music at the very beginning of modernity, via Schopenhauer, Nietzsche and Heidegger, to post-structuralism, needs, then, to be examined in this perspective. Debates about the political implications of deconstruction have much to gain from studying this aspect of aesthetic theory, not least because the missing dimension of the subject that is not simply an 'effect of the general text' (Derrida) cannot be ignored in such theory. Despite the repeated references to postmodernity in these debates, they are in many respects being carried on in the terms largely established in the Romantic period of modern philosophy. Given the fraught history of the politics of this aspect of German philosophy, a historical awareness of the sources of these theoretical issues is vital if old mistakes are not to be repeated.

\section{Notes}

1 I am thinking of the kind of analysis which reduces Schumann's Frauenliebe und Leben to its place in an ideology of gender in the nineteenth century. The text of the cycle may belong in such a context, but to hear the music solely in these terms is not to hear it at all.

2 Clearly this is only going to be successful against a background of verbal communication which enables the conductor to play such a role, but what is at issue here are the aspects of communication which go beyond what can be said. Why otherwise do the conductors not just tell the orchestra what to do verbally?

3 It is perhaps worth mentioning here that Davidson regards metaphor as the 'dreamwork of language'.

4 Such an account of music would, of course, fail to take into account the fact that the division of the harmonic series is not natural, because it is historically changeable. The fact that the changes can be expressed in mathematical proportions does not explain why, for example, there is a move from untempered to tempered scale.

5 The composers clearly did so in ways that were also influenced by philosophical, literary 
and other ideas, but the mistake is to think that what they did and the effect of what they did is solely the result of such influences. The point of the early Romantics' insights here, as we shall see, is that they were the first to see that music itself could affect conceptual thinking.

6 The same can even be said of the way we apprehend a painting.

7 Mallarmé was familiar with some of Hegel's work.

8 The ambiguity here between the epistemological use of the term to designate immediate self-consciousness, and the use to designate feeling as affect can be resolved by the fact that both fit Novalis's dictum that 'feeling cannot feel itself'. The point is that neither is inherently propositional.

9 It is worth remembering here that the analytical philosophy of mind has often focused on facts like pain, which are inadequately discussed in terms of propositional knowledge.

10 This, of course, connects Saussure's ideas to contemporary inferentialism.

11 It is often claimed that Schumann does not fully grasp Heine's irony, which would indeed seem to be the case. However, he can also be understood as revealing the source of that irony by revealing the pain and longing that lies beneath it.

12 In Brandom's terms the subject is understood as that which can grasp the conceptual content of an articulation, rather than being what is merely the locus of a differential response. As I suggested above, this does not seem enough to account for what is at issue in music.

13 This attempt, of course, ignores Schleiermacher's hermeneutic point that understanding the purified language relies on first having learned a natural language via which the world is intelligible at all.

14 Representation therefore is just understood as a one-to-one correlation of a word to a thing, without any sense that the essence of the thing is adequately conveyed by the word.

15 There is a way of making such connections, and of using aspects of 'objective spirit' to understand deeper historical trends, but the methods for doing this are still essentially contested, so making totalising judgements in terms of them is problematic.

16 On this see Davidson's 'A Nice Derangement of Epitaphs' in Lepore 1984.

17 Wittgenstein's notion of family resemblance can suggest what is meant here.

18 See Charles Lewis (1985): 'Kant and E.T.A. Hoffmann: "The Sandman”', in Ideas and Production 3, pp. 28-43. The structure is rather like the one observed in relation to Hölderlin's idea of poetic representation in Chapter 3.

19 This is only one way of reading Schelling's text: I suggested some provisos in Chapter 4.

20 It should not be forgotten here that Schlegel can be considered the founder of serious literary history, but that is only part of his wider aims.

21 Adorno's difficulties in finishing his work on Beethoven seem to relate to the sense that his admiration of Beethoven's work, and his conviction that Beethoven is yet symptomatic of the wider failure of German culture cannot easily co-exist. 